\title{
Hybrid Learning Using Canvas LMS
}

\begin{tabular}{|c|c|}
\hline ABSTRACT & \\
\hline $\begin{array}{l}\text { Hybrid learning refers to the learning style where online components are } \\
\text { used to replace some face-to-face elements of the course. In the current } \\
\text { era, where COVID-19 pandemic has highly impacted higher education, } \\
\text { online and remote forms of learning have become critical success factors } \\
\text { to deliver engaging and rich teaching and learning experience to the } \\
\text { students. With the partial return of face-to-face interaction with the } \\
\text { students this year after easing restrictions, universities have no choice but } \\
\text { to offer hybrid learning experience. In the journey towards this type of } \\
\text { learning, a transition in both pedagogy and vehicle (tools) is inevitable. } \\
\text { Hybrid learning pedagogy has been in literature for many years now and } \\
\text { many institutions worldwide have enough experience to run courses and } \\
\text { programs as a hybrid model. For the vehicle, a number of tools are } \\
\text { necessary to facilitate delivery, but the most important tool is obviously } \\
\text { the learning management system (LMS). Canvas LMS is now considered } \\
\text { one of the most commonly used electronic learning systems, offering a } \\
\text { large number of features and options to make teaching and learning easier } \\
\text { and effective for both teachers and students. In this paper, two hybrid } \\
\text { learning models are proposed. An example of implementing one of the two } \\
\text { models using Canvas LMS and other supporting tools is provided. } \\
\text { Anecdotal student feedback has shown that the students were highly } \\
\text { engaged and their experience has been improved as a result of the hybrid } \\
\text { delivery format. }\end{array}$ & $\begin{array}{l}\text { Published Online: November 15, } 2021 \\
\text { ISSN: 2736-4534 } \\
\text { DOI :10.24018/ejedu.2021.2.6.180 } \\
\text { Ali Al-Ataby* } \\
\text { University of Liverpool, Liverpool, UK. } \\
\text { (e-mail: aliataby@liverpool.ac.uk) } \\
\text { *Corresponding Author }\end{array}$ \\
\hline $\begin{array}{l}\text { Keywords: Canvas, face-to-face teaching, hybrid, LMS, online } \\
\text { teaching, VLE. }\end{array}$ & \\
\hline
\end{tabular}

\section{INTRODUCTION}

Hybrid teaching and learning combines the benefits of both face-to-face and online teaching styles together in a cohesive manner. It is often confused with other teaching styles such as blended or even flipped learnings [1]. Ideally, hybrid learning aims at balancing both face-to-face and online styles (about 50/50 \% split), while blended learning classically has more face-to-face elements but incorporates a few online components (about $75 / 25 \%$ split) [2]. In the meantime, and because of the ongoing COVID-19 pandemic, institutes are more inclined towards more online elements than face-to-face because of health implications until the negative effect of the pandemic fades away. Moreover, in case of further lockdowns due to anticipated COVID-19 outbreaks, it will be easier and less disrupting to switch the limited number of face-to-face components to online without jeopardizing student learning experience. Accordingly, online teaching components are more preferable in the meantime if possible by all means, nevertheless face-to-face teaching must also be incorporated to promote the necessary engagement and social interaction amongst the students and also between the students and the teachers. Thus, hybrid learning offers the best experience in the meantime, if it is combined with careful planning, staff training, students-teachers' collaboration and keen institutions [1].

Hybrid learning offers flexibility, not only in terms of time, but also in delivery and the use of teaching tools, compared to the classical face-to-face teaching where only one teaching style is followed. Students can access material at any time and interact with learning resources at their own pace, and they can assess their learning independently. Moreover, online style helps the less vocal students to become strong contributors and makes them more visible and keener to reflect on their learning and provide feedback about their experience to their instructors. On the other hand, with the face-to-face interaction in hybrid learning (and in general), real-time engagement can be achieved along with prompt feedback about the learning process, with the opportunity of teachers to adapt delivery based on student interaction and visual cues, things that are very difficult to forge in onlineonly delivery. Moreover, face-to-face teaching style fosters collegial relationships amongst the students and their teachers, creating a better engagement and social interaction. In particular, exercises such as groupwork (discussions, projects, presentations) and problem class sessions and 
tutorials are best carried out in face-to-face style to achieve their intended learning outcomes [2].

From the above discussion, it can be seen that each of the two teaching styles (face-to-face or online) has its own unique merits that don't exist in the other style, and by adopting a well-planned hybrid learning, the features of both styles are combined into a single one to form a powerful, rich and engaging learning experience [3]. Moreover, research studies have also suggested that hybrid teaching style has led to a more efficient use of physical teaching resources (such as classrooms, libraries and laboratories) in universities and other educational institutions, and it is cited in many references as being the most effective teaching format in recent years [2], [4], [5].

To implement a successful hybrid teaching style, tools and resources are required, in addition to careful planning, staff training and institution willingness to introduce change. Apart from human resource factor (which is very crucial), information technology tools are key success factor to deliver successful hybrid learning because they are the vehicle to implement this teaching style. In particular, the LMS (aka the virtual learning environment or VLE) is considered very significant because it provides the single point of contact and the virtual platform for students and teachers to interact outside the face-to-face bubble [6], [7]. There are obviously a number of VLEs used by educational institutions worldwide, and it is out of the scope of this paper to explore the features of these or suggest the best ones to use.

In this paper, two hybrid learning models are proposed. An example of implementing one of the two models using Canvas LMS and other supporting tools is provided.

This paper is organized as follows:

- Section II provides a brief literature review about hybrid learning.

- Section III illustrates the proposed hybrid learning models (two models will be presented).

- Section IV provides implementation details and the obtained results.

- Section $\mathrm{V}$ provides recommendations for Hybrid Learning Delivery.

- Section VI provides concluding comments.

\section{LiteratURE REVIEW}

In the last decade or so, hybrid teaching style has been extensively practiced and many research studies have been conducted to confirm its effectiveness and assess its impact on student experience and engagement. All studies have shown that hybrid teaching is without a doubt the style of choice by the students because it helped them to achieve their learning targets in an efficient way compared to either faceto-face or online teaching alone.

Here is a sample of research studies about hybrid learning:

[5]: In this study, a hybrid learning model is developed on Brightspace platform. The model utilized web-based technology and its main feature was being user-friendly. The model offered video conferencing and online discussion features. The model was very convenient to use and, accordingly, has improved user experience.

[8]: In this study, hybrid learning style was reviewed and its benefits were studied, and the result was that it provides flexible, cost-effective and rich alternative over classical delivery styles. The study also emphasized on the importance of providing adequate training for all the staff involved in delivering hybrid learning. The study advised institutions to address weaknesses in the social aspects of hybrid delivery.

[9]: In this study, the challenges of hybrid learning such as student engagement, persistence and achievements were studies and investigated. The study provided methods to address these challenges and has shown that the proposed methods have managed to tackle these challenges.

[4]: In this study, hybrid learning is studied and its features were identified. The study showed that it provides flexible learning approach in terms of learner needs, the course and pace, time and space. However, the study concluded that despite the aforementioned benefit, the adoption of hybrid learning has been slow in some areas due to some cost implications, social effects on learners, integration and applicability.

[10]: In this study, key components to design an effective hybrid learning course are identified and discussed. The study also aimed at highlighting the role of network and mobile technologies to enhance hybrid learning. Also, the study provided a model of hybrid teaching using MOOC (or massive open online course).

Hybrid learning delivery can also be designed according to the open-license ABC learning model proposed by University College London (UCL) in 2018. For adoption of this model by other universities and higher education institutions, it is highly recommended that this model to be integrated in the process of curriculum thinking and development, taking into consideration the six $\mathrm{ABC}$ model learning types: Acquisition, Investigation, Discussion, Practice, Collaboration and Production [11].

\section{PROPOSED HYBRID LEARNING MODELS}

There is no exact science about the style and format of hybrid learning model, and each educational institution delivering hybrid modules/courses has its own version and flavor. It should be emphasized that a hybrid delivery model is not about taking half of the material, class sessions or activities in a module or course and convert these to online, but rather to connect what is in the face-to-face part (mediated by humans) and the online part (mediated by technology) in a seamless way (integrating both experiences) to avoid ending up converting a module into two parallel and unconnected modules.

The following are the starting key points when thinking about designing a hybrid learning model:

a) In hybrid delivery, the focus should be on the design and integration of the module rather than the technology used.

b) Both types of sessions (in particular, the online) must be designed in a way to be active and engaging.

c) A hybrid model is not just about accessing resources electronically in the LMS/VLE or other web-based tools but it is about the design and implementation of activities with students.

d) Integration between the two components must be seamless to avoid delivering two unconnected 
experiences.

In this paper, two models for hybrid delivery are proposed. These are lecture/topic-based and task/assignment-based models.

\section{A. Lecture/Topic-Based Model}

In this model, the hybrid delivery is designed with respect to module topics. Depending on module syllabus and timetable, new topics are introduced every week or even every session. There are four steps in this model that are categorized into: before-class, class and after-class activities. These are summarized as follows:

a) Before-class activities (online, asynchronous):

i. Step 1: Preparing a pre-recorded video for the topic(s). It is recommended not to make such video long (based on student feedback, they preferred short videos no longer than 20 minutes or so). These should obviously be prepared by lecturers beforehand and the students are required to go through these (along with other supporting material in the VLE) before the timetabled class session.

ii. Step 2: Introducing an online activity about the topic(s). This could be in the form of an online test/quiz or any other forms and could carry weight (summative) or be just formative. The idea of such test or activity is to create student curiosity, interest and questions about the given topic. Moreover, this activity provides prompt feedback, so students know immediately if they have revised enough and understood the given topic or not.

b) Class activities (face-to-face, synchronous):

Step 3: In this step, face-to-face interaction is carried out. This session can be organized as a Q\&A session with either real-time questions by the students or questions that were collected beforehand (through a dedicated discussion board or by other means). This could also be a problem class session, a tutorial, project work or group discussion exercise. The length of this session depends on the purpose, timetable flexibility and lecturer and room availability.

c) After-class activities (online, asynchronous)

Step 4: In this step, another chance to check understanding is provided, so an activity about the discussed topic(s) is introduced. This could be summative or formative, depending on module assessment structure. An online quiz would be a good option because it provided prompt feedback about understanding, but a discussion question, or even an essay exercise could be used as activities in this step.

Discussion boards are online asynchronous tools that play an important role in any hybrid learning experience in general. In the last step of the above model, after-class discussion board is used to collect general feedback, or in case there are remaining questions about the introduced topics. Also, it could be used to establish the required links to the upcoming topics or allure students' interest about real-life applications of the discussed topic.

The above steps need to be reflected in the VLE in the right order and format, and accessibility of material and components must be controlled in an adaptive way, so they could be released after all the required prerequisites are checked. This feature is available in most of the commonly used VLEs (including Canvas).

Fig. 1 shows a block diagram of the proposed model discussed above.

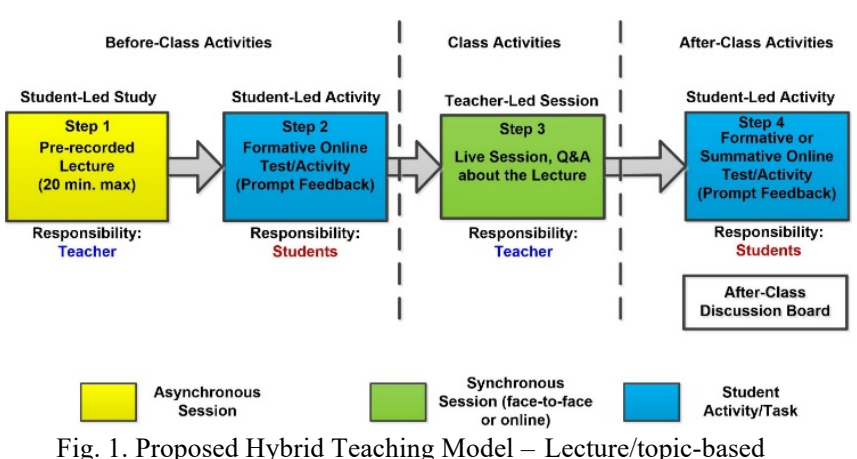

\section{B. Task/Assignment-Based Model}

In this model, the hybrid delivery is designed with respect to the assignments or tasks of the module. This model is more suitable for modules assessed completely by coursework assignments or they have a high percentage of weight on coursework activities. There are five steps in this model that are categorized into before-class, class and after-class activities. These are summarized as follows:

a) Before-class activities (online, asynchronous):

i. Step 1: Preparing a pre-recorded video for the topic that will be assessed in the coursework assignment, and a 20-minute video could be enough for this purpose. It should obviously be prepared by lecturers beforehand, and students are required to go through these (along with other supporting material in the VLE) before the timetabled class session.

ii. Step 2: Preparing a video about the coursework assignment, where the lecturer goes through all the requirements and states also what is expected from the students (e.g. length of the report to be submitted, the format, the software required...etc.).

b) Class activities (face-to-face, synchronous):

Step 3: In this step, face-to-face interaction is carried out. This session is organized to respond to students' questions about assignment requirements or even about the topics that are covered in the assignment. These can be real-time questions by the students or collected beforehand. The lecturer could go through example of good and poor assignment report or anything else that is related to assignment.

c) After-class activities (online, asynchronous)

i. Step 4: In this step, the coursework assignment is released to the students and they are expected to submit their work before a deadline. The students may still have questions about the assignment meanwhile, and in this case a discussion board is used to capture such questions (one discussion board could be used for all assignments or one for each).

ii. Step 5: In this step, a recoded feedback video is 
provided to the students. This video is meant to provide a generic feedback about student's attempts and things to avoid when working on future coursework assignments. The students will also be getting a personalized feedback about their attempts along with their marks.

Fig. 2 shows a block diagram of the proposed model discussed above. As with the first model, the above steps need to be reflected in the VLE in the right order, format and accessibility restrictions, and there is an after-class discussion board that is utilized to sum up findings, link to the upcoming assignments and provide real-life applications of the topic and assignment.

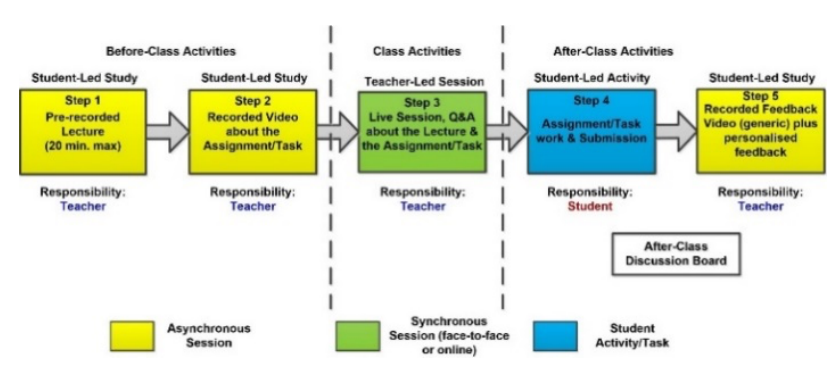

Fig. 2. Proposed Hybrid Teaching Model - Task/assignment-based

\section{IMPLEMENTATION AND RESULTS}

In this section, an implementation of lecture/topic-based hybrid teaching model on Canvas LMS is going to be illustrated only (task/assignment-based model won't be implemented in this study). Canvas is a reliable, easy-to-use, web-based virtual learning environment that helps educational institutions to manage learning and allows both learners and educators to interact and collaborate in one place. It is one of the most commonly used VLEs in recent years due to its large number of features and educational applications. It can host learning material with different formats (documents, videos, audio...etc.) and provides a variety of assessment methods to student work. It is integrated with many other existing educational technologies and software packages, so it can be used as a single-point of contact and collaboration.

A hybrid learning module can be easily implemented in Canvas LMS. Fig. 3 shows an example of a module (course) implemented in Canvas that is designed as a hybrid module. This example follows the lecture/topic-based model discussed in the previous section.

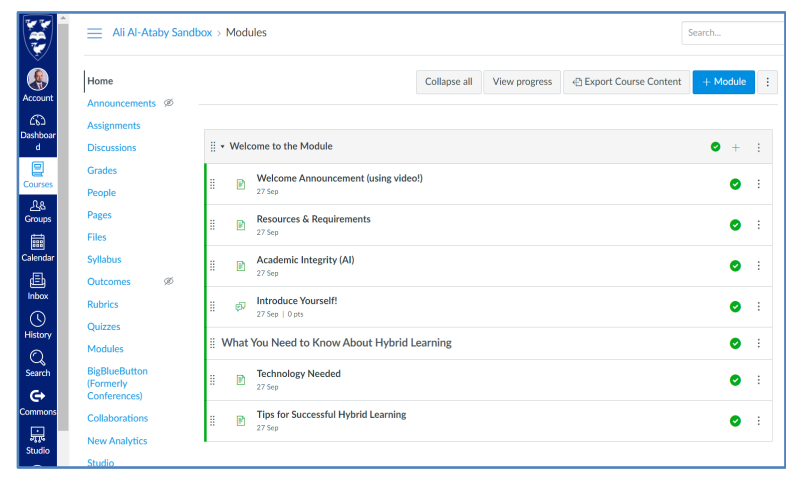

Fig. 3. Hybrid learning module example in Canvas LMS

The module consists of a number of units, organized in a weekly way, so there are 12 units to cover one semester (the semester is assumed to have 12 weeks in this implementation). There is an additional unit, which is called "Welcome to the Module", and it is the first unit in module contents, illustrated in Fig. 4. This unit provides important introduction to the module and it is a prerequisite for other units to become available to the students. Each module could have different items to show in this unit, and in the proposed example, the following items are suggested:

a) Welcome Announcement, which is preferably done as a short video prepared by the lecturer to introduce the module and provide important information about it.

b) Resources and Requirements, which provides a list of resources (references, website links...etc.) and requirements (e.g. prerequisites).

c) Additional Information, such as Academic Integrity policy or any other important information that students need to know before taking this module.

d) Introduce Yourself, which is a discussion board that is used by the students to introduce themselves to their peers and also to the lecturer. They could post their favorite photo and talk briefly about their background, hobbies and interests.

e) What you need to know about Hybrid learning, which provides information about hybrid learning in the form of short video, a website link or a document. Information about the required technology (e.g. PC/iPad/Tablet needed and their specs, Internet speed, camera, audio accessories, software packages and browser version...etc.) must also be provided so that all the students are aware of the hardware and software they will be using in the module to avoid any confusion. Also, for the benefit of students who are new to this, tips for successful hybrid learning could be made available to the students so they know how to deal with such delivery format and what to expect as well. It is also recommended to mention the benefits of hybrid learning with some example so the students can appreciate the efforts put into the module to remodel it this way.

Fig. 4 illustrates the "Welcome to the Module" unit. It should be mentioned that more information could be added, depending on the module and its prerequisites. Also, a background check quiz (formative) could be incorporated as means for the students to check their background suitability to study the module.

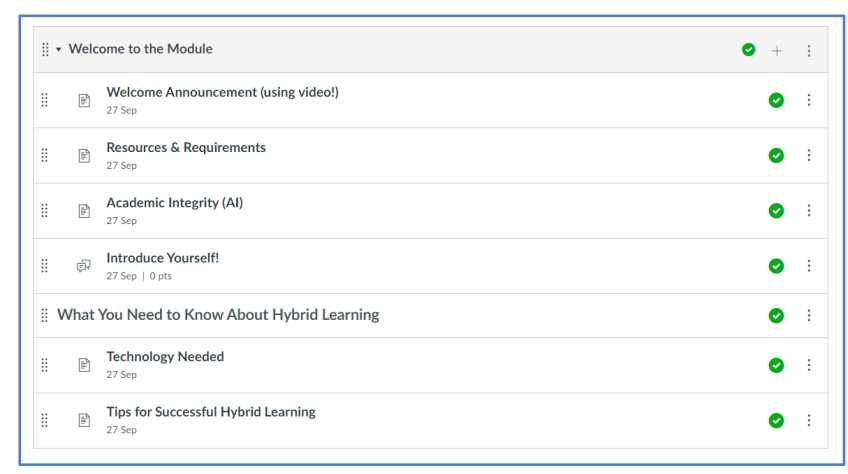

Fig. 4. "Welcome to the Module" unit

As said before, the proposed hybrid module is organized as weekly content units (could be organized per topics as well). 
Fig. 5 shows the structure of a weekly unit, which is based on the model shown in Fig. 1. The unit is divided into three subunits: before-class, class and after-class activities. For the first unit (or Week 1) to become available, students must go through the prerequisite first, which is "Welcome to the Module" unit and satisfy all of its requirements. Similarly, Week 2 unit has Week 1 unit as its prerequisite, and so on.

Before-class activities consist of the following:

a) Lecture or week objectives and activities, which provides the objectives of the week and the activities involved, so students know exactly what is the plan for this week.

b) Lecture or topic material and documents, which links to all the lecture notes and documents required for this week.

c) Pre-recorded lecture, which is a video prepared by the lecturer about the topic(s). As said before, students tend to like short videos rather than long ones.

d) Background check quiz, which is a formative test to confirm student understanding of the given topic after reading the lecture note and watching the pre-recorded video. This quiz has unlimited number of attempts, so students can do it as many times as they want, and could be designed to have random questions each time it begins.

\begin{tabular}{|c|c|}
\hline : • Week 1 Activities (Topic Titles/Week/Dates) & Prerequilistes: Welcome to the Module $0+$ \\
\hline :: Before-Class Activities & - \\
\hline : $\quad$ : Lecture/Week Objectives and Activities & - \\
\hline : 国 Lecture/Topic Document Material & - \\
\hline :: $\quad$ Pre-recorded Lecture & - \\
\hline : \& Background Check Quiz (formative) & $\bullet$ \\
\hline : Class Activities & - \\
\hline :1 Live Lecture, Zoom/Teams Link & $\bullet$ \\
\hline :: $\quad$ S Slides/Material & $\bullet$ \\
\hline :ः After-Class Activities & - \\
\hline : A After-Class Discussion & - \\
\hline : $\&$ Assignment (Formative/Summative) & - \\
\hline
\end{tabular}

Fig. 5. Hybrid model weekly unit

Class activities consist of the following:

a) Live lecture information and Zoom/Teams Link, which provides timetable information about the session (date, time and location) and also a link for those who won't be able to join physically but online only (e.g. through Zoom or MS Teams).

b) Slides/Material/Video, which provides all the material (PPT slides, problem sheets...etc.) required for the live class session. Also, this link could provide a recorded video for the live class session for future reusability by the students.

After-class activities consist of the following:

a) After-class discussion, which is a discussion board to capture remaining student questions and also to open general discussions about the discussed topic and its reallife applications.

b) Assignment, which is either summative or formative quiz (or any other form of assessment) for final confirmation of student understanding.

It is also recommended to have other content units (other than the weekly units) for ease of accessibility. Fig. 6 shows a proposed list of such content units. For example, all recorded videos produced for each week could be added to one place (called Videos and Podcasts for example), all assignments links in one place, all discussion boards in one place, and so on.
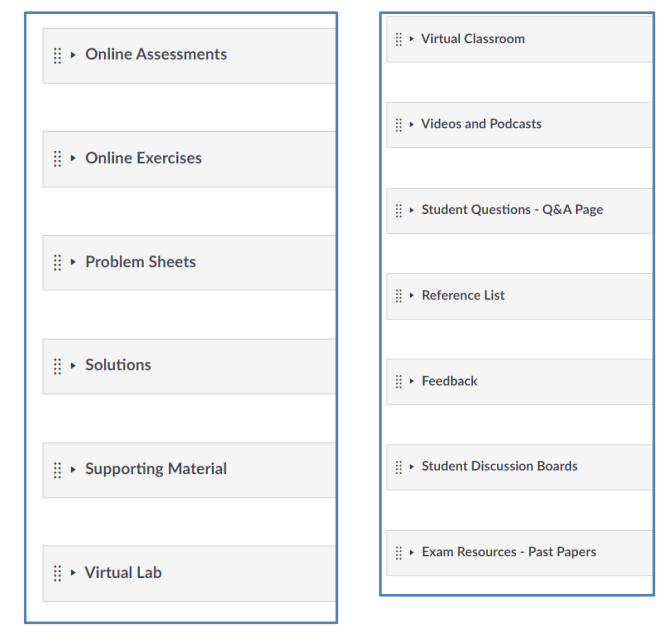

Fig. 6. Additional contents units used in the Hybrid Module

To facilitate the successful delivery of the hybrid module, a number of tools are needed. These tools are either available in Canvas LMS already or are external. Table I shows a list of the suggested tools, their use and whether they can be used for face-to-face or online part of the hybrid delivery. It should be mentioned that some of the online tools provided in the table can be used for either synchronous online, asynchronous online or for both synchronous and asynchronous online deliveries.

TABLE I. TOOLS USED FOR THE HYBRID DELIVERY

\begin{tabular}{|c|c|c|}
\hline Tools & Use & Face-to-face/Online \\
\hline $\begin{array}{l}\text { Poll Everywhere, } \\
\text { Kahoot!, } \\
\text { Mentimeter }\end{array}$ & $\begin{array}{l}\text { Real-time } \\
\text { (formative) } \\
\text { assessments, } \\
\text { feedback collection, } \\
\text { background } \\
\text { assessment }\end{array}$ & $\begin{array}{l}\text { Face-to-face and online } \\
\text { (synchronous) }\end{array}$ \\
\hline $\begin{array}{l}\text { Canvas Online } \\
\text { Test }\end{array}$ & $\begin{array}{l}\text { Summative and } \\
\text { formative } \\
\text { assessments }\end{array}$ & $\begin{array}{l}\text { Online (synchronous, } \\
\text { asynchronous) }\end{array}$ \\
\hline Canvas Studio & $\begin{array}{l}\text { Pre-recorded } \\
\text { lectures, } \\
\text { induction/instruction } \\
\text { videos }\end{array}$ & Online (asynchronous) \\
\hline Canvas Chat & $\begin{array}{l}\text { Collaborations, } \\
\text { student support, } \\
\text { virtual office hours }\end{array}$ & Online (synchronous) \\
\hline $\begin{array}{l}\text { Canvas Discussion } \\
\text { Boards }\end{array}$ & $\begin{array}{l}\text { Offline discussions, } \\
\text { collaboration, Q\&A } \\
\text { page, feedback } \\
\text { collection }\end{array}$ & Online (asynchronous) \\
\hline MS Teams & $\begin{array}{l}\text { Live online lectures, } \\
\text { virtual office hours, } \\
\text { live Q\&A sessions }\end{array}$ & Online (synchronous) \\
\hline $\begin{array}{l}\text { MS Teams } \\
\text { Channels }\end{array}$ & $\begin{array}{l}\text { Document sharing, } \\
\text { discussions, } \\
\text { answering student } \\
\text { questions, } \\
\text { announcements, } \\
\text { reminders }\end{array}$ & Online (asynchronous) \\
\hline Zoom & $\begin{array}{l}\text { Live online lectures, } \\
\text { virtual office hours, } \\
\text { live Q\&A sessions }\end{array}$ & Online (synchronous) \\
\hline
\end{tabular}




$\begin{array}{lll}\begin{array}{l}\text { Microsoft Forms, } \\ \text { Google Forms }\end{array} & \begin{array}{l}\text { Feedback collection, } \\ \text { attendance } \\ \text { monitoring, } \\ \text { information } \\ \text { collection } \\ \text { Live question } \\ \text { collection, feedback } \\ \text { collection }\end{array} & \begin{array}{l}\text { Online (synchronous, } \\ \text { asynchronous) }\end{array} \\ \text { TextWall } & \begin{array}{l}\text { Face-to-face and online } \\ \text { Simulations and } \\ \text { GeoGebra and }\end{array} & \begin{array}{l}\text { Face-to-face and online } \\ \text { (synchronous and }\end{array} \\ \text { MATLAB online/ } & \begin{array}{l}\text { Demoding } \\ \text { exercise and } \\ \text { assessment }\end{array} & \text { asynchronous) }\end{array}$

Anecdotal feedback collected from the students about their experience of the hybrid module has shown a high satisfaction with respect to the delivery using the above tools and the format. Attendance was high every week and kept improving over the period of running the module (it should be emphasized that attendance is not a measure for engagement, though).

FiFig. 7 shows the attendance of the live classes of the module in question for a period of 9 weeks where this study was conducted. It should be mentioned here that due to a further lockdown, the live classes were conducted in a synchronous online format.

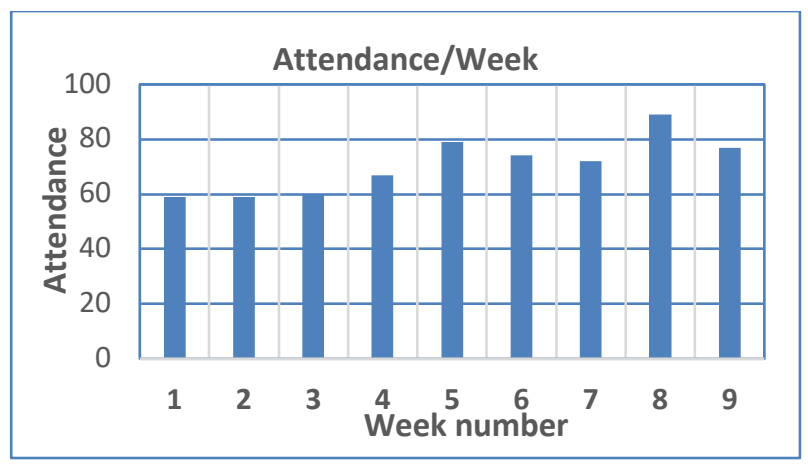

Fig.7. Attendance per week of the hybrid module

As can be seen from the above figure, attendance was generally improving every week and hasn't dropped below week 1 numbers, which is an indication that the students have found these sessions very useful and helped the online delivery of the hybrid module. The total number of students that were registered in this module was 130 and it was run in first semester of 2020-21 session. It should be noted here that attendance was voluntary (optional) only for that session.

Fig. 8 shows the weekly average satisfaction rate on a score of 1 to 5 for the live classes of the module for a period of 9 weeks as well. As can be seen from the figure, satisfaction score was above 4.5 (out of 5) for all the weeks, which is an indication that the students have found these sessions very helpful and engaging, and their experience has been improved as a result of the hybrid delivery format.

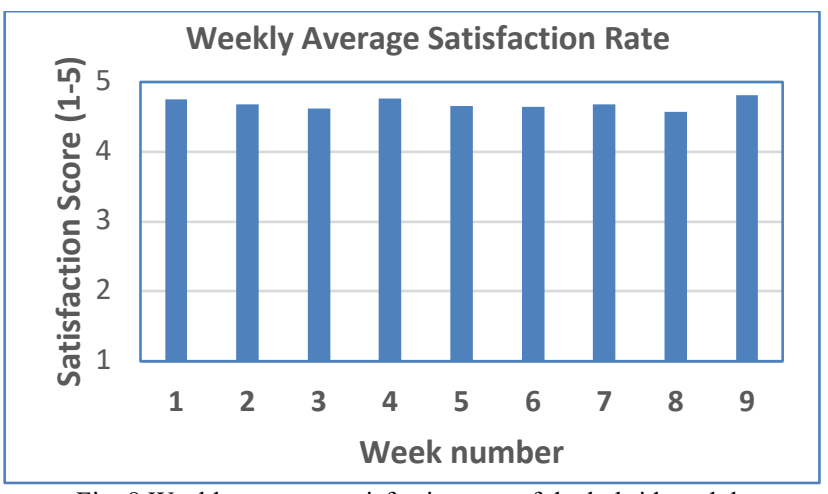

Fig. 8 Weekly average satisfaction rate of the hybrid module

\section{RECOMMENDATIONS FOR HYBRID LEARNING DELIVERY}

In this section, a number of recommendations for new implementers of hybrid learning modules are provided:

a) Successful and smooth hybrid delivery is about the seamless integration between face-to-face and online components.

b) In hybrid learning, the sessions (in particular, the faceto-face ones) must be engaging, otherwise, students will switch off and prefer complete online delivery.

c) Keep in mind that hybrid learning is not just about providing resources in an online way, but it is about designing and implementing activities in an engaging way.

d) A good starting point for hybrid delivery is to categorize module's learning outcomes as can be achieved by faceto-face or online delivery, then thinking of the implementation and integration.

e) Manage students' expectations, avoid last minute surprises and improve transparency. Make sure that the students know exactly what is meant by hybrid learning.

f) Avoid loading the module with additional contents, activities and assignments. Also, make sure not to overload yourself with additional tasks or spending much time in perfecting minor things.

g) Be ready for negative feedback from the students. Also, expect facing problems especially when running this for the first time.

h) For new implementations, it is better to start by introducing small changes in a gradual and incremental way rather than major changes at once.

i) The focus of hybrid delivery must not be on the technology, but the design and integration of activities between the face-to-face and online components. Start with basic technology tools first and introduce the advanced ones later after students get use to the new delivery format.

j) Discussion boards, which are online asynchronous collaboration tools, play an important role in hybrid (and online) learning experience in general, so they are highly recommended in hybrid courses.

k) Ask for feedback from colleagues (especially the experienced with hybrid learning) and students continuously. Don't collect feedback at a late stage of the semester/year to be able to respond to student feedback as early as possible.

1) It is always a good idea to start implementing hybrid delivery with high level modules because students are 
more experienced and can adapt quickly with changes.

\section{CONCLUSIONS}

Hybrid learning has been growing very fast in the last few years (especially during COVID-19 pandemic years for obvious reasons). It combines the benefits of both face-toface and online teaching styles together in a cohesive manner. There is no exact science about its style and format, and each educational institution delivering hybrid modules has its own version and flavor. All studies about hybrid learning have shown that it is without a doubt the style of choice by the students because it helped them to achieve their learning targets in an efficient way compared to either face-to-face or online teaching alone.

It should be emphasized that in hybrid delivery, the focus should be on the design and integration of the module rather than technology used. Both types of sessions (in particular, the online) must be designed in a way to be active and engaging. A hybrid model is not just about accessing resources electronically in the LMS/VLE or other web-based tools but it is about the design and implementation of activities with students. Furthermore, the integration between the two components must be seamless to avoid delivering two unconnected modules or activities.

In this paper, two hybrid learning models were proposed. An example of implementing one of the two models using Canvas LMS and other supporting tools is provided. Anecdotal student feedback has shown that students were highly engaged and their experience has been improved as a result of the hybrid delivery format.

\section{ACKNOWLEDGMENT}

The author would like to thank the staff of the Department of Electrical Engineering and Electronics, University of Liverpool, for their support. Also, thanks are extended to the staff of the Computer Services Department (CSD) and the Centre for Innovation in Education (CIE) in the University of Liverpool for their continuous help, advice and encouragements.

\section{REFERENCES}

[1] A. Al-Ataby, "Technology-Enhanced Learning and Teaching in COVID-19 Era: Challenges and Recommendations," International
Journal for Innovation Education and Research, vol. 8, no. 10, pp. 317 $331,2020$.

[2] DuPage, (Aug 2020), Learning Technologies - An Introduction to Hybrid Teaching. [Online]. Available: https://www.codlearningtech.org/PDF/hybridteachingworkbook.pdf.

[3] B. Anthony Jr. et al., "Blended Learning Adoption and Implementation in Higher Education: A Theoretical and Systematic Review. Tech Know Learn, 2020.

[4] S. M. Alnajdi, "Hybrid Learning in Higher Education," Society for Information Technology \& Teacher Education, 2014.

[5] T. Handayani, J. Kalengkongan, A. Marini and M. Sumantri, "Developing hybrid learning models platform based on user experience," IOP Conference Series: Materials Science and Engineering, vol. 1098, 2021.

[6] A. Al-Ataby and W. Al-Nuaimy, "Technology-Enhanced and Personalised Laboratory Learning Experience for Undergraduate Electrical Engineering and Electronics Students," International Journal for Innovation Education and Research, vol. 7, no. 10, pp. 534$550,2019$.

[7] A. Al-Ataby, "Innovative teaching tools for large multicultural cohorts in electrical engineering and electronics," 11th European Workshop on Microelectronics Education (EWME), 2016.

[8] W. A. Young, L. Allen and K. Warfield, "Developing Online/Hybrid Learning Models for Higher Education," Jacksonville: Jacksonville State University, 2016.

[9] Gleason, B. W. \& Greenhow, C., 2017. Hybrid Learning in Higher Education: The Potential of Teaching and Learning with RobotMediated Communication. Education Publications, 21(4).

[10] Trentin, G. \& Bocconi, S., 2014. The Effectiveness of Hybrid Solutions in Higher Education: A Call for Hybrid-Teaching. Educational Technology, 54(5), pp. 12-21.

[11] UCL, (May 2018), ABC Learning Design@ UCL. [Online] Available: https://blogs.ucl.ac.uk/abc-ld/.

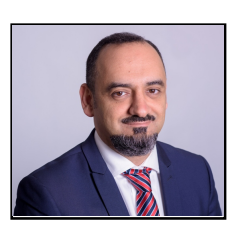

Ali Al-Ataby got his $\mathrm{PhD}$ degree in Signal Processing and Machine Learning from the Department of Electrical Engineering and Electronics, University of Liverpool, Liverpool, UK in 2012.

He worked in industry as well as academia since 1997. He joined the University of Liverpool since 2011 as a lecturer, and he is currently a senior lecturer (associate professor). His current research interest is centered around devising automatic interpretation algorithms for non-destructive testing data, with a particular interest in visual, ultrasonic and radar data. Further interests are in biomedical signal/data processing (e.g. EEG, ECG and DNA data) and driver fatigue detection/prediction. Other research interests include machine learning, embedded systems and FPGAs. He is highly interested in Technology Enhanced Education and Pedagogical Research as well.

Dr Al-Ataby is a Senior Fellow of the UK Higher Education Academy and is a Chartered Engineer (CEng) recognized by the Institute of Engineering and Technology (IET), UK. He has won two prestigious awards, which are "The Sir Alastair Pilkington Award for Teaching Excellence" and the "Faculty of Science and Engineering Learning and Teaching Award", University of Liverpool. 